\title{
Random response analysis of axle-box bearing of a high-speed train excited by crosswinds and track irregularities
}

\begin{abstract}
The Axle-box bearing (ABB) is a key component in the high-speed train which suffers multiple stochastic excitations in realistic working conditions. The ABB's health status is crucial for the reliable and safe operation of the rolling stock. This paper proposes a novel stochastic vehicle-track coupled model to evaluate the dynamic performance of $\mathrm{ABBs}$ in a high-speed train with unsteady wind load and random track irregularities. The nonlinear bearing stiffness and unsmooth nonlinearities of the bearing clearances are properly considered based on the Hertzian contact theory. The von Karman power spectral density is adopted to generate the time-history of the fluctuating wind speed on a moving vehicle. The unsteady wind loads acting on the carbody are derived based on the fluid-induced vibration theory. The empirical PSD of track irregularity is adopted to generate the time-history of track irregularities. The Monte Carlo method is employed to analyse the roller-raceway contact stress with random excitations of unsteady wind and track irregularities. The results indicate that the crosswind causes the partial loading phenomenon of the ABBs. The increase of crosswind speed significantly increases the probability of the contact stress exceeding the safety threshold, which challenges the service safety of the key components inside the train.
\end{abstract}

Index Terms-High-speed train, axle-box bearing, stochastic characteristics, track irregularities, fluctuating crosswind.

\section{INTRODUCTION}

$\mathrm{T}$ he last two decades have witnessed an extensive development of high-speed train worldwide, as it has significant advantages of high reliability, safety, high speed, and environmental friendliness. The ever-increasing running speeds and complex service environments lead to various types of technical issues, challenging the safety and the reliability of high-speed trains [1]. One of them is to ensure the regular operation of the components inside the train without traffic disruption. As is well known, the axle-box bearings are the crucial connector between the bogie frame and the wheelset. In any case, this is the only source of driving force for the highspeed train. Often, the ABBs adopt the double-row tapered roller bearings (TRBs), which suffer the loads from the vehicle, as well as the excitations from the wheel-rail interface. The abnormal status of the ABBs directly deteriorates the service performance of the high-speed train, which may even cause fatal accidents such as the rollover and derailment [2], [3]. Therefore, the ABBs within high-speed trains should be kept at health status to ensure the safe and stable operation of highspeed railway.

Most of the previous studies focus on the dynamic performance of the vehicle at high speed [4]-[6]. However, a lot of them focus on the vehicle or the vehicle-track system without the consideration of the ABBs. Generally, the vehicle model has been developed from the traditional multi-rigid-body model to the advanced rigid-flexible coupling model [7], [8]. At a conventional speed, the coupling effects between a vehicle and the track system are not significant [4] - [9]. As the speed's increasing, the interaction between the wheel and rail plays a more critical role in affecting the vehicle dynamics [10]. Using the vehicle-track coupling model, wheel-rail interaction has been extensively studied in [11]-[13]. These works indicate that track irregularity is the main source of vehicle vibration, and it is also the dominant factor affecting the wheel-rail interaction. Moreover, the track irregularity causes the vibration of the bridges [14], [15]. Apart from the track irregularity, the crosswind is another main disturbance to the vehicle, and it has a significant influence on the vehicle or vehicle-track coupled systems, especially at high speeds [16], [17]. In a realistic operation environment of a high-speed train, the vehicle is generally excited by both track irregularities and crosswinds [18]. Previous researches mainly study the effects of the track irregularities and the crosswind on the running safety of the vehicle and the wheel-rail interaction. However, the safety status of key components inside the train, especially the ABBs, have not been concerned.

Some studies on the TRBs without considering the complicated working environments, such as the analysis of the dynamics [20], [21], fault diagnosis, and condition monitoring [22]-[24], have been widely performed in the past years. Regarding the dynamic model, Palmgren [25], Jones [26], and Harris [27] are the pioneers, who develop the theoretical basis for the rolling element bearing. Based on the underlying theory, Andreason [28] develops the TRB model to investigate the load distribution between the roller and the raceways by considering the combined radial and axial loads. However, the centrifugal and gyroscopic moments are neglected in this model. S. Kabus et al. [29] investigate the contact pressure distributions of the TRBs via a developed multi-degree of freedom model. Some other works also address the effects of angular misalignment and geometric error on the TRBs [30], [31], and evaluate the roller-raceway contact forces, contact stress, and stiffness characteristics. However, the abovementioned literature mainly focuses on single-row TRBs. Regarding double-row TRBs, Becrea et al. [32], [33] investigate the fatigue life and heat dissipation via an analytical model considering the bearing clearance, centrifugal, and pre-compression. Yang et al. [34] propose a mathematical model considering the angular misalignment of double-row TRBs with combined external loads to study their contact state and fatigue life. However, the performance of $\mathrm{ABBs}$ inside the high-speed train with the 
random excitations of track irregularities and stochastic crosswind has not been concerned in previous researches.

In this article, the shortfall in previous studies is addressed, and a novel vehicle-track coupled model is proposed considering the TRBs based on the author's previous work [35]. Using the empirical PSD function, the stochastic crosswind on the moving vehicle is generated. The realistic track irregularities are obtained using the standard PSD function special for China high-speed network. Then the dynamic interactions within the ABBs are investigated in the time and frequency domains. On the idea Monte Carlo Method (MCM), a stochastic analysis procedure is presented to evaluate the roller-raceway contact stress with random excitations of unsteady wind and track irregularities.

\section{WIND-VEHICLE-TRACK COUPLED MODEL}

A wind-vehicle-track coupled model is developed to inclusive of the ABBs within the coupled systems, as shown in Figs. 1 and 2. It is comprised of a vehicle sub-model, a track sub-model, and a wheel-rail interaction sub-model. Each of them is described in detail below.

\section{A. Vehicle sub-model}

The vehicle consists of the car body, bogie frames, wheelsets, traction motors, gearboxes, and axle-boxes. All of them are regarded as rigid bodies, as shown in Fig. 1 and Fig. 2. The connections between vehicle components are performed by spring and damper elements. Nonlinearities (e.g., air springs and vertical and yaw dampers) are also considered herein. A total of 23 rigid bodies of the vehicle systems have 102 degrees of freedom. Apart from the ABBs, the models of other components have been fully illustrated in previous works [13], [35], which are not described repetitively here.

Fig. 3 shows the ABBs model, the dynamic interaction between the roller and the raceways is modelled based on the Hertzian contact theory. The rollers and inner raceways are regarded as a whole body. The dynamic force $Q_{\text {mej }}$ between the rollers and the outer raceway can be evaluated by [36]

$$
Q_{\mathrm{mej}}=35948 L_{w}^{8 / 9} \delta_{\text {mej }}^{10 / 9}
$$

where $m$ is the row number and $l_{w}$ represents the effective contact length of the rollers, $\delta_{\mathrm{m} e j}$ is the compression.

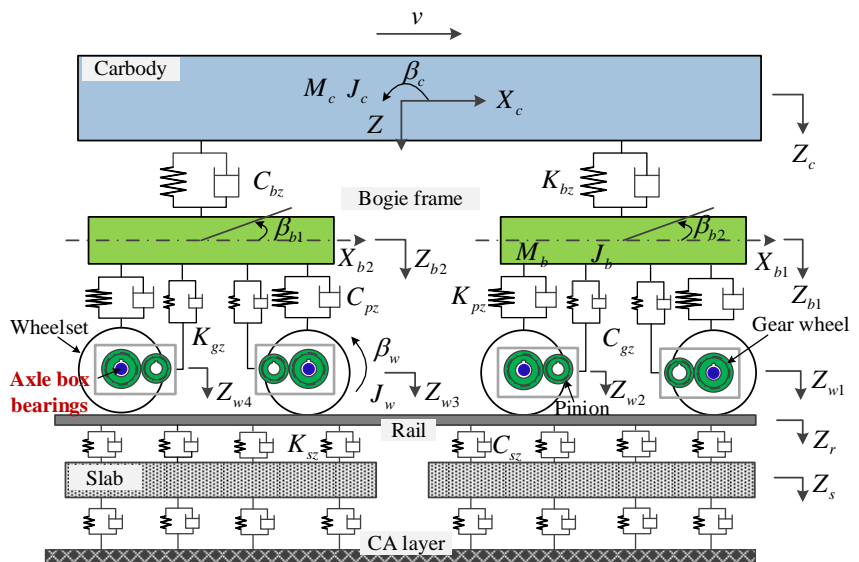

Fig. 1. Vehicle-track coupled dynamics model in the elevation view.

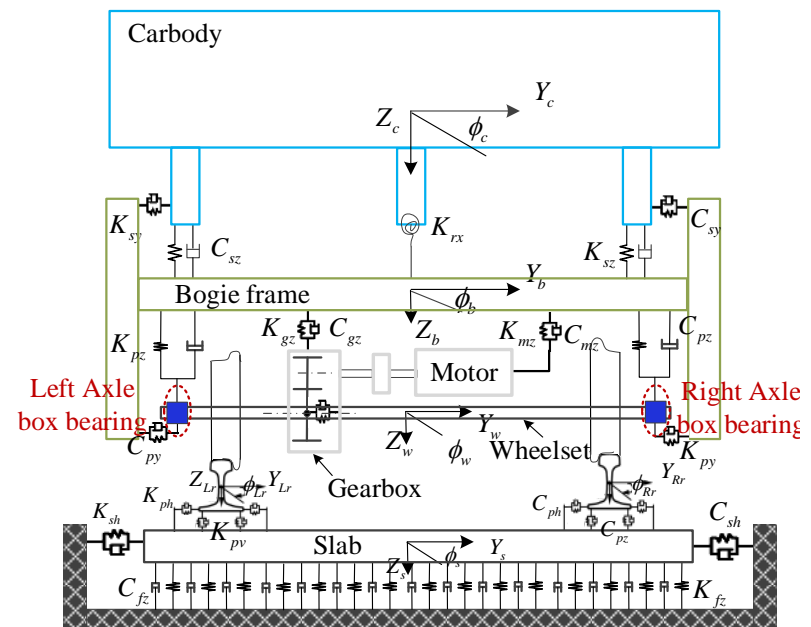

Fig. 2. Vehicle-track coupled dynamics model in the end view.

The force $Q_{\mathrm{mi}}$ between the roller and the inner raceway, and those between the roller and guiding flange of the inner raceway $Q_{\mathrm{mf}}$ can be calculated by

$$
\left\{\begin{array}{l}
Q_{\mathrm{mi}}=Q_{\mathrm{me}} \frac{\sin \left(\alpha_{\mathrm{e}}+\alpha_{\mathrm{f}}\right)}{\sin \left(\alpha_{\mathrm{i}}+\alpha_{\mathrm{f}}\right)}-\frac{1}{2} m d_{m} \omega_{c}^{2} \frac{\sin \left(\alpha_{\mathrm{f}}\right)}{\sin \left(\alpha_{\mathrm{i}}+\alpha_{\mathrm{f}}\right)} \\
Q_{\mathrm{mf}}=Q_{\mathrm{me}} \frac{\sin \left(\alpha_{\mathrm{e}}-\alpha_{\mathrm{f}}\right)}{\sin \left(\alpha_{\mathrm{i}}+\alpha_{\mathrm{f}}\right)}+\frac{1}{2} m d_{m} \omega_{c}^{2} \frac{\sin \left(\alpha_{\mathrm{i}}\right)}{\sin \left(\alpha_{\mathrm{i}}+\alpha_{\mathrm{f}}\right)}
\end{array}\right.
$$

where $\alpha_{\mathrm{i}}, \alpha_{\mathrm{e}}$, and $\alpha_{\mathrm{f}}$ are the contact angles of the roller-inner raceway, roller-outer raceway, and roller-guiding flange, respectively (Fig. 3); $d_{m}$ is the pitch diameter of the TRBs, and $\omega_{c}$ is the orbital angular speed of the rollers obtained by

$$
\omega_{\mathrm{c}}=\frac{\omega_{\mathrm{w}}}{2 d_{m}}\left(d_{m}-d_{r} \cos \frac{\alpha_{i}+\alpha_{e}}{2}\right)
$$

where $\omega_{\mathrm{w}}$ is the angular speed of the wheelset and $d_{r}$ is the mean diameter of the rollers.

The compression of the roller at the azimuthal location $\psi_{j}$ can be calculated by

$$
\begin{aligned}
\delta_{m e j}= & {\left[\delta_{\mathrm{r}} \cos \psi_{j}-0.5 \mathrm{~g}_{\mathrm{h}}\left(1-\cos \psi_{j}\right)\right] \cos \alpha_{\mathrm{e}} } \\
& -(-1)^{m} \delta_{y} \sin \alpha_{\mathrm{e}}, \quad(m=1,2, \text { and } j=1-21)
\end{aligned}
$$

where $\delta_{\mathrm{r}}$ and $\delta_{y}$ are the relative radial and axial displacements between the inner and outer raceways, respectively, which are obtained by

$$
\left\{\begin{array}{l}
\delta_{r}=\sqrt{\left(X_{a}-X_{w} \pm d_{w} \psi_{w}\right)^{2}+\left(Z_{a}-Z_{w} \pm d_{w} \phi_{w}\right)^{2}} \\
\delta_{y}=Y_{a}-Y_{w}
\end{array}\right.
$$

(a)

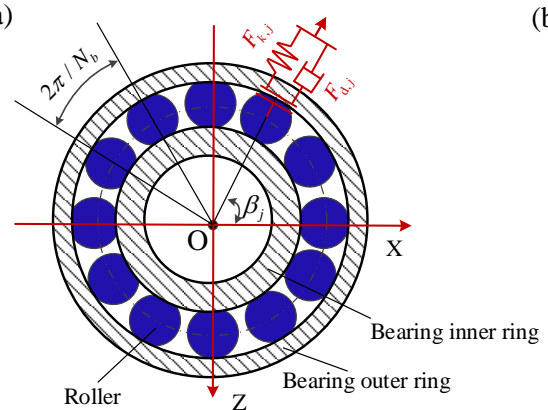

b)

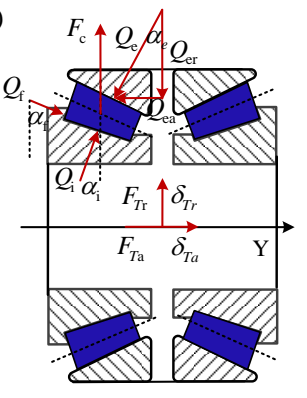

Fig. 3. ABBs of a high-speed train. 
where $X_{a}$ and $X_{w}$ are the longitudinal displacements of axlebox and wheelset, respectively; $\phi_{w}$ and $\psi_{w}$ are the roll and yaw motions of the wheelset, respectively; $Y_{a}$ and $Y_{w}$ are the lateral displacements of the axlebox and wheelset, respectively. Hence, the dynamic forces between the roller and the raceways can be calculated using Eqs. (1) - (5). The resultant forces of each $\mathrm{ABB}$ in the radial $\left(F_{\mathrm{r}}\right)$ and axial $\left(F_{a}\right)$ directions can be calculated as follows:

$$
\left\{\begin{array}{l}
F_{\mathrm{r}}=\sum_{m=1}^{2} \sum_{j=1}^{21} Q_{m e j} \cos \alpha_{\mathrm{e}} \cos \psi_{m j}+C_{\mathrm{a}}\left(\dot{X}_{\mathrm{a}}-\dot{X}_{\mathrm{w}} \pm \dot{\psi}_{\mathrm{w}} d_{w}\right) \\
F_{a}=\sum_{m=1}^{2} \sum_{j=1}^{21} Q_{m e j} \sin \alpha_{\mathrm{e}}+C_{a}\left(\dot{Y}_{a}-\dot{Y}_{w}\right)
\end{array}\right.
$$

where $C_{\mathrm{a}}$ is the bearing damping. Hence, the nonlinear dynamic forces of ABBs are applied on the axle-box and wheelset simultaneously in the simulation to achieve the integration of the TRBs and the vehicle-track coupled system, respectively.

Finally, the equations of motion for the vehicle subsystem are presented as follows based on multibody dynamics [13]:

$$
\mathbf{M}_{\mathrm{v}} \ddot{\mathbf{X}}_{\mathrm{v}}+\mathbf{C}_{\mathrm{v}} \dot{\mathbf{X}}_{\mathrm{v}}+\mathbf{K}_{\mathrm{v}} \mathbf{X}_{\mathrm{v}}=\mathbf{F}_{\mathrm{WR}}+\mathbf{F}_{\mathrm{ext}}
$$

where $\mathbf{X}_{\mathrm{V}}, \dot{\mathbf{X}}_{\mathrm{V}}$, and $\ddot{\mathbf{X}}_{\mathrm{V}}$ are the displacement, velocity, and acceleration vectors of the vehicle system, respectively, and $\mathbf{M}_{\mathrm{v}}, \mathbf{C}_{\mathrm{v}}$, and $\mathbf{K}_{\mathrm{v}}$ are the mass, damping, and stiffness matrices of the vehicle system, respectively. $\mathbf{F}_{\mathrm{WR}}$ is a vector of the nonlinear wheel-rail contact forces, and $\mathbf{F}_{\mathrm{ext}}$ is a vector of the external forces, such as traction, aerodynamic, and vehicleoperation resistance forces.

Hence, the roller-raceway contact forces are obtained in the service environments of high-speed trains, and the maximum contact stress can be further derived as follows [36]:

$$
\left\{\begin{array}{l}
\sigma_{\text {max }}=\frac{2 Q_{i}}{\pi L_{w} \sqrt{\frac{4 Q_{i}}{\pi L_{w} \sum \rho_{i}}\left(\frac{1-v_{1}^{2}}{E_{1}}+\frac{1-v_{2}^{2}}{E_{2}}\right)}} \\
\sigma_{\text {omax }}=\frac{2 Q_{e}}{\pi L_{w} \sqrt{\frac{4 Q_{e}}{\pi L_{w} \sum \rho_{o}}\left(\frac{1-v_{1}^{2}}{E_{1}}+\frac{1-v_{2}^{2}}{E_{2}}\right)}}
\end{array}\right.
$$

where $\sigma_{i \max }$ and $\sigma_{\text {omax }}$ are the maximum roller-inner and outer raceway contact stress values, respectively; $\sum \rho_{i}$ and $\sum \rho_{o}$ are the contact ratios of the roller-inner and outer raceways, respectively; $v_{1}$ and $v_{2}$ are the Poisson ratios of the roller and raceways, respectively; $E_{1}$ and $E_{2}$ are the elasticity modulus of the roller and raceways, respectively.

\section{B. Track submodel}

A typical slab-track system is established, which comprises rails, slabs, and subgrades (Figs. 1 and 2). The rail is supported by the slab and modelled as a Timoshenko beam [37], and the dynamic equations describing the lateral and vertical vibrations are given below:

$$
\begin{aligned}
& M_{r} \frac{\partial^{2} y_{r}\left(x_{r}, t\right)}{\partial t^{2}}+\kappa_{r y} G_{r} A_{r}\left[\frac{\partial \psi_{z r}\left(x_{r}, t\right)}{\partial x_{r}}-\frac{\partial^{2} y_{r}\left(x_{r}, t\right)}{\partial x_{r}^{2}}\right] \\
& =-\sum_{i=1}^{N r s} F_{s y i} \delta\left(x_{r}-s_{s i}\right)+\sum_{i=j}^{N w} F_{w r y i} \delta\left(x_{r}-s_{w j}\right) \\
& M_{r} \frac{\partial^{2} z_{r}\left(x_{r}, t\right)}{\partial t^{2}}+\kappa_{r z} G_{r} A_{r}\left[\frac{\partial \psi_{y r}\left(x_{r}, t\right)}{\partial x_{r}}-\frac{\partial^{2} z_{r}\left(x_{r}, t\right)}{\partial x_{r}^{2}}\right] \\
& =-\sum_{i=1}^{N r s} F_{s z i} \delta\left(x_{r}-S_{s i}\right)+\sum_{i=j}^{N w} F_{w r i z} \delta\left(x_{r}-s_{w j}\right)
\end{aligned}
$$

The equations describing the torsional and bending stiffness values of the rail are given as follows:

$$
\begin{gathered}
\rho_{r} I_{0 r} \frac{\partial^{2} \psi_{x r}\left(x_{r}, t\right)}{\partial t^{2}}+K_{r x} \frac{\partial^{2} \psi_{x r}\left(x_{r}, t\right)}{\partial x_{r}^{2}} \\
=-\sum_{i=1}^{N r s} M_{s i} \delta\left(x_{r}-x_{s i}\right)+\sum_{j=1}^{N w} M_{w r x i} \delta\left(x_{r}-x_{w i}\right) \\
\rho_{r} I_{y r} \frac{\partial^{2} \psi_{y r}\left(x_{r}, t\right)}{\partial t^{2}}+\kappa_{r z} G_{r} A_{r}\left[\psi_{y r}\left(x_{r}, t\right)-\frac{\partial z_{r}\left(x_{r}, t\right)}{\partial x_{r}}\right] \\
-E_{r} I_{r y} \frac{\partial^{2} \psi_{r y}\left(x_{r}, t\right)}{\partial x_{r}^{2}}=0 \\
\rho_{r} I_{z r} \frac{\partial^{2} \psi_{z r}\left(x_{r}, t\right)}{\partial t^{2}}+\kappa_{r y} G_{r} A_{r}\left[\psi_{z r}\left(x_{r}, t\right)-\frac{\partial y_{r}\left(x_{r}, t\right)}{\partial x_{r}}\right] \\
-E_{r} I_{r z} \frac{\partial^{2} \psi_{r z}\left(x_{r}, t\right)}{\partial x_{r}^{2}}=0
\end{gathered}
$$

The rail parameters in Eqs. (9)-(13) are as follows: mass $M_{r}$ per unit length; mass density $\rho_{r}$; lateral and vertical shear coefficients $\kappa_{r y}$ and $\kappa_{r z}$, respectively; torsional stiffness $K_{r x}$; shear modulus and cross-sectional area $G_{r}$ and $A_{r}$, respectively; polar inertia moment $I_{0 r}$; rail-area second moments of the cross-section around the $y$ and $z$ axes ( $I_{y r}$ and $I_{z r}$ respectively); $N_{r s}$ and $N_{w}$ are the number of rail supports and wheelsets, respectively; $F_{s y}$ and $F_{s z}$ are the forces exerted by the slab in the $y$ and $z$ directions, respectively; $F_{w r y}$ and $F_{w r z}$ are the forces caused by the wheel-rail contact in the $y$ and $z$ directions, respectively; and $M_{w r x}$ and $M_{s}$ are the moments of the wheelsets and the slabs, respectively.

The flexible vertical deformation of the slab is considered as a plate [12], and its vertical vibration is governed by

$$
\begin{aligned}
& \frac{\partial^{4} w(x, y, t)}{\partial x^{4}}+2 \frac{\partial^{4} w(x, y, t)}{\partial x^{2} \partial y^{2}}+\frac{\partial^{4} w(x, y, t)}{\partial y^{4}} \\
& +\frac{C_{s}}{D_{s}} \frac{\partial w(x, y, t)}{\partial t}+\frac{\rho_{s} h_{s}}{D_{s}} \frac{\partial^{2} w(x, y, t)}{\partial t^{2}} \\
& =\frac{1}{D_{s}}\left[\sum_{i=1}^{N_{p}} F_{s v i}(t) \delta\left(x-x_{p i}\right) \delta\left(y-y_{p i}\right)\right. \\
& \left.-\sum_{j=1}^{N_{b}} F_{C A v j}(t) \delta\left(x-x_{b i}\right) \delta\left(y-y_{b j}\right)\right]
\end{aligned}
$$


where $w(x, y, t)$ denotes the vertical deformations of the slab; $C_{\mathrm{s}}$ and $D_{\mathrm{s}}$ are the damping and bending stiffness values, respectively; $\rho_{s}$ and $h_{\mathrm{s}}$ are the slab density and thickness, respectively; and $N_{\mathrm{p}}$ and $N_{\mathrm{b}}$ are the number of rail fasters and supporting points of the slabs, respectively.

Using the modal superposition method, the governing equations of the rails and the slabs are expressed by ordinary differential equations. Therefore, the vibration equations of the slab-track submodel are given as follows:

$$
\mathbf{M}_{\mathrm{T}} \ddot{\mathbf{X}}_{\mathrm{T}}+\mathbf{C}_{\mathrm{T}} \dot{\mathbf{X}}_{\mathrm{T}}+\mathbf{K}_{\mathrm{T}} \mathbf{X}_{\mathrm{T}}=\mathbf{F}_{\mathrm{WR}}
$$

where $\mathbf{M}_{\mathrm{T}}, \mathbf{C}_{\mathrm{T}}$, and $\mathbf{K}_{\mathrm{T}}$ are the mass, damping, and stiffness matrices of the slab-track system, respectively; $\mathbf{X}_{\mathrm{T}}$ denotes the generalized coordinates of the slab-track system; and $\mathbf{F}_{\mathrm{WR}}$ is a vector of the nonlinear contact forces at the wheel-rail interface.

\section{Wheel-rail interaction sub-model}

The dynamic interactions of vehicle and track subsystems are achieved by the wheel-rail interaction. In the wheel-rail interface, the dynamic forces are comprised of the normal contact forces and tangential creep forces. These are determined by the geometric and motion states of both wheels and rails. The same wheel-rail interaction model in the nominal and tangential forces employed in the literature [13], is adopted herein.

\section{RANDOM TRACK IRREGULARITIES AND CROSSWINDS}

The random track irregularities and the unsteady crosswinds used in the simulation are described below.

\section{A. Random track irregularities}

The track irregularities are categorized into four types: lateral, vertical, roll, and gauge irregularities. The standard spectral density function derived from the measurement data from China high-speed networks is adopted in this work, which is expressed as follows [38]

$$
S(f)=\frac{A}{f^{k}}
$$

where $f$ is the spatial frequency; $A$ and $k$ are the fitting coefficients. The time-history of track irregularities is generated by the inverse Fourier transformation [38]. The frequency spectrum $X(k)$ is obtained by discrete sampling from the standard spectral density function. The real and imaginary parts of $X(k)$ have even and odd symmetries with respect to $N_{r} / 2$. Hence, the frequency spectrum $X(k)\left(k=0,1, \ldots, N_{r} / 2\right)$ is determined as follows:

$$
X(k)=|X(k)|\left(\cos \phi_{k}+i \sin \phi_{k}\right) \quad\left(k=0,1, \ldots, N_{r} / 2\right)
$$

where $\phi_{k}$ is the phase angle and obeys the uniform distribution of $0 \sim 2 \pi$, and $N_{r}$ denotes the sampling points. Then, the track irregularities are calculated using inverse Fourier Transform as

$$
x(n)=\frac{1}{N_{r}} \sum_{k=0}^{N_{r}-1} X(k) \exp \left[\frac{i 2 \pi k n}{N_{r}}\right] \quad\left(n=0,1, \ldots, N_{r}-1\right)
$$

\section{B. Random crosswinds}

The Cooper theory in the form of a von Karman power spectral density, which is denoted as the dimensionless power spectral density functions of the wind velocity in the longitudinal and

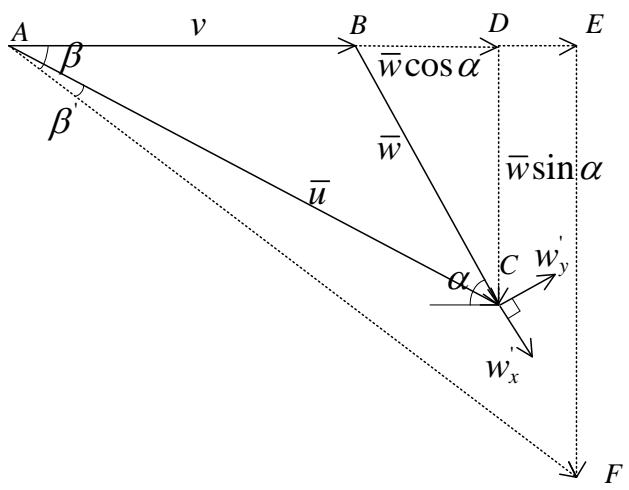

Fig. 5. Schematics of vector components.

lateral directions at a moving point, is adopted in the investigation [39]:

$$
\begin{aligned}
\frac{n S_{w x}}{\sigma_{w x}^{2}} & =\frac{4\left(n L_{x}^{\prime} / \bar{u}\right)}{\left(1+70.8\left(n L_{x}^{\prime} / \bar{u}\right)^{2}\right)} \\
& \times\left[C_{w x}^{2}+\left(1-C_{w x}^{2}\right) \frac{0.5+94.4\left(n L_{x}^{\prime} / \bar{u}\right)^{2}}{1+70.8\left(n L_{x}^{\prime} / \bar{u}\right)^{2}}\right] \\
\frac{n S_{w y}}{\sigma_{w y}^{2}} & =\frac{4\left(n L_{y}^{\prime} / \bar{u}\right)}{\left(1+70.8\left(n L_{y}^{\prime} / \bar{u}\right)^{2}\right)} \\
& \times\left[C_{w y}^{2}+\left(1-C_{w y}^{2}\right) \frac{0.5+94.4\left(n L_{y}^{\prime} / \bar{u}\right)^{2}}{1+70.8\left(n L_{y}^{\prime} / \bar{u}\right)^{2}}\right]
\end{aligned}
$$

In Equations (19) and (20),

$$
\begin{gathered}
C_{w x}=\frac{v \cos \alpha+w}{\bar{u}} \\
L_{x}^{\prime}=L_{w x}^{x}\left(C_{w x}^{2}+4\left(\frac{L_{w x}^{y}}{L_{w x}^{x}}\right)^{2}\left(1-C_{w x}^{2}\right)\right)^{0.5} \\
C_{w y}=\frac{v \sin \alpha}{\bar{u}} \\
L_{y}^{\prime}=L_{w y}^{y}\left(C_{w y}^{2}+4\left(\frac{L_{w y}^{x}}{L_{w y}^{y}}\right)^{2}\left(1-C_{w y}^{2}\right)\right)^{0.5}
\end{gathered}
$$

where $\frac{n S_{w x}}{\sigma_{w s}^{2}}$ and $\frac{n S_{w y}}{\sigma_{w y}^{2}}$ are the dimensionless power spectral densities of $w_{x}^{\prime}$ and $w_{y}$, respectively; $S_{w x}$ and $S_{w y}$ are the power spectral densities of $w_{x}^{\prime}$ and $w_{y}^{\prime}$, respectively; $L_{w x}^{x}$ and $L_{w x}^{v}$ are the longitudinal and lateral integral length scales of $w_{x}^{\prime}$ and $w_{y}^{\prime}$, respectively; $L_{w y}^{x}$ and $L_{w y}^{y}$ are the longitudinal and lateral integral length scales of $w_{x}^{\prime}$ and $w_{y}^{\prime}$, respectively; $\sigma_{w x}$ and $\sigma_{w y}$ are the standard deviations of $w_{x}^{\prime}$ and $w_{y}^{\prime}$, respectively; and $\bar{u}$ is the relative speed of the mean wind given as follows:

$$
\bar{u}=\sqrt{v^{2}+\bar{w}^{2}+2 v \bar{w} \cos \alpha}
$$

The standard deviations and integral length scale defined in [40] are adopted in this work. The longitudinal $\left(w_{x}^{\prime}\right)$ and lateral $\left(w_{y}^{\prime}\right)$ 


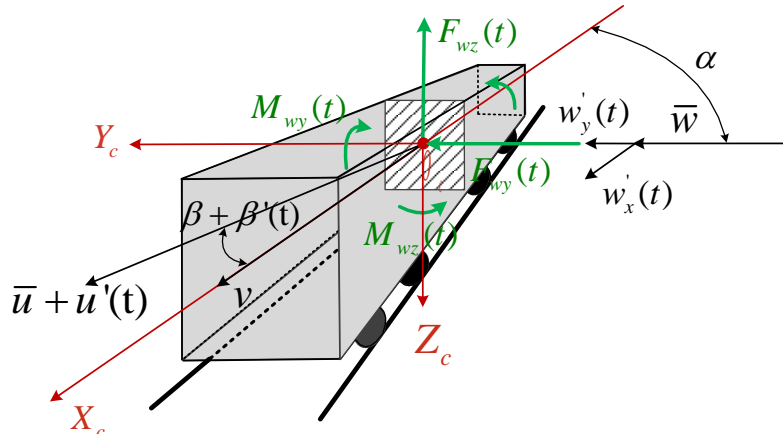

Fig. 4. Wind load diagram of the vehicle system.

fluctuation winds in the time domain can be calculated by the harmonic superposition method as follows:

$$
\left\{\begin{array}{l}
w_{x}^{\prime}(t)=\sum_{j}\left[2 S_{w x}\left(n_{j}\right) \Delta n_{j}\right]^{0.5} \sin \left(2 \pi n_{j} t+2 \pi p_{j}\right) \\
w_{y}^{\prime}(t)=\sum_{j}\left[2 S_{w y}\left(n_{j}\right) \Delta n_{j}\right]^{0.5} \sin \left(2 \pi n_{j} t+2 \pi q_{j}\right)
\end{array}\right.
$$

where $\Delta n_{j}$ represents the frequency interval; $p_{j}$ and $q_{j}$ are the coefficients obeying the normal distribution of $0 \sim 1$.

Fig. 4 shows the vehicle's wind load diagram. The dynamic forces applied to the vehicle can be calculated as follows when the wind excitations are obtained:

$$
F=\bar{F}+F^{\prime}=0.5 \rho \operatorname{AC}_{F}(\beta)\left[\bar{u}+u^{\prime}(t)\right]^{2}
$$

where $\rho$ is the air density, $A$ is the reference area of the vehicle and $\mathrm{C}_{F}(\beta)$ is the aerodynamic force coefficient relative to the yaw angle $\beta$. The mean forces $(\bar{F})$ and moments $(\bar{M})$ can be calculated as follows [17]:

$$
\begin{gathered}
\bar{F}=0.5 \rho A \bar{C}_{F} \bar{u}^{2} \\
\bar{M}=0.5 \rho A H \bar{C}_{M} \bar{u}^{2}
\end{gathered}
$$

The unsteady aerodynamic forces $\left(F^{\prime}\right)$ and the moments $\left(M^{\prime}\right)$ are calculated by:

$$
\begin{aligned}
F^{\prime} & =\rho A \bar{C}_{\mathrm{F}} \bar{u} u^{\prime}+0.5 \rho A \bar{C}_{\mathrm{F}}^{\prime} \beta^{\prime} \\
M^{\prime} & =\rho A \bar{C}_{\mathrm{M}} \bar{u} u^{\prime}+0.5 \rho A \bar{C}_{\mathrm{M}}^{\prime} \beta^{\prime}
\end{aligned}
$$

Fig. 5 shows a vector diagram that relates the mean wind speed $\bar{w}$, wind direction $\alpha$, vehicle velocity $v$, longitudinal and lateral fluctuating wind speed $w_{x}^{\prime}$ and $w_{y}^{\prime}$.Through the geometrical relationship of $\triangle \mathrm{ABC}, \triangle \mathrm{ADC}$ and $\triangle \mathrm{AEF}$, it is obtained as:

$$
\begin{aligned}
& \beta^{\prime} \approx \frac{v \sin \alpha}{\bar{u}^{2}} w_{x}^{\prime}-\frac{(v \cos \alpha+\bar{w})}{\bar{u}^{2}} w_{y}^{\prime} \\
& u^{\prime} \approx \frac{v \sin \alpha}{\bar{u}} w_{y}^{\prime}+\frac{(v \cos \alpha+\bar{w})}{\bar{u}} w_{x}^{\prime}
\end{aligned}
$$

Substituting (32) and (33) into (30) and (31) yields:

$$
\begin{aligned}
& F^{\prime}=\rho A\left[\bar{C}_{F} v \sin \alpha-0.5 \bar{C}_{F}^{\prime}(v \cos \alpha+\bar{w})\right] w_{y}^{\prime} \\
& +\rho A\left[\bar{C}_{F}(v \cos \alpha+\bar{w})+0.5 \bar{C}_{F}^{\prime} v \sin \alpha\right] \\
& \times \int_{0}^{\infty} h_{F}(\tau) w_{x}^{\prime}(t-\tau) d \tau
\end{aligned}
$$
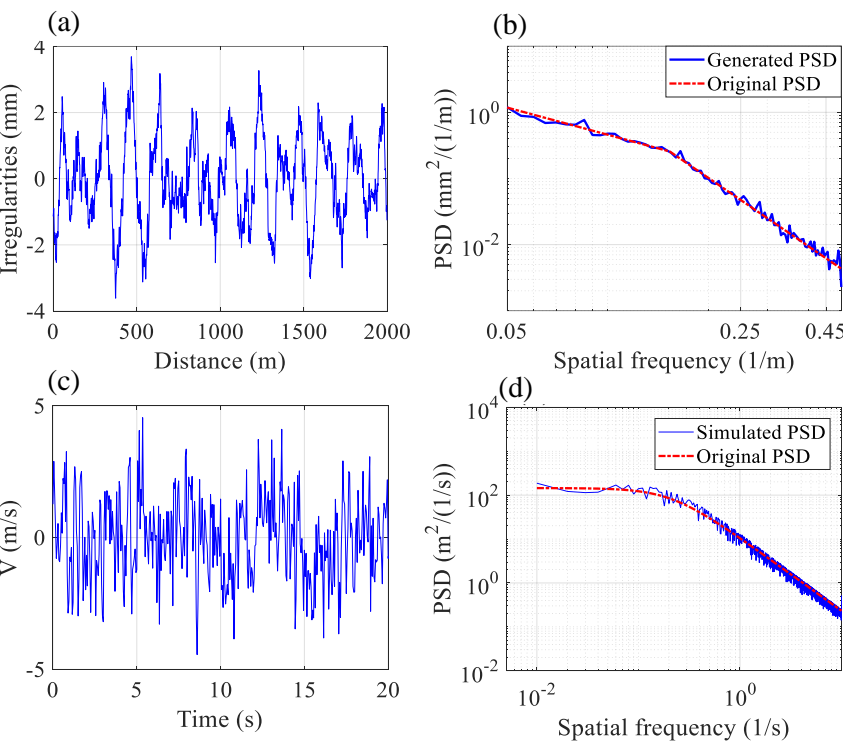

Fig. 7. Track geometric random irregularities in the (a) spatial and (b) PSD forms; fluctuating crosswinds in the (c) temporal and (d) PSD forms.

$$
\begin{aligned}
& M^{\prime}=\rho A H\left[\bar{C}_{M} v \sin \alpha-0.5 \bar{C}_{M}^{\prime}(v \cos \alpha+\bar{w})\right] w_{y}^{\prime} \\
& +\rho A H\left[\bar{C}_{M}(v \cos \alpha+\bar{w})+0.5 \bar{C}_{M}^{\prime} v \sin \alpha\right] \\
& \times \int_{0}^{\infty} h_{F}(\tau) w_{x}^{\prime}(t-\tau) d \tau
\end{aligned}
$$

where $H$ is the reference height; $\bar{C}_{F}$ and $\bar{C}_{F}$ are the aerodynamic force coefficient, and its derivation at the mean yaw angle $\bar{\beta}$, respectively; $\bar{C}_{M}$ and $\bar{C}_{M}$ are the aerodynamic moment coefficient and its derivation at the mean yaw angle $\bar{\beta}$, respectively; and $h_{F}(\tau)$ is the aerodynamic weighting function describing the time delay phenomenon.

The aerodynamic force and moment coefficients presented in Fig. 6 are adopted in this work. These coefficients are measured by the wind tunnel experiment on a typical China high-speed train [41]. The crosswind aerodynamic forces acting on the vehicle system are obtained using Eqs. (28) - (35).

\section{MODEl VALIDATION}

Track geometric random irregularities and crosswinds are complex and essential to affect the vehicle-track coupled dynamic performance. Fig. 7 (a) shows the time-history of track irregularities generated by the inverse Fourier transformation method. Fig. 7 (b) shows the comparison of simulation and the target spectrums. It is seen that the simulation spectrum shows

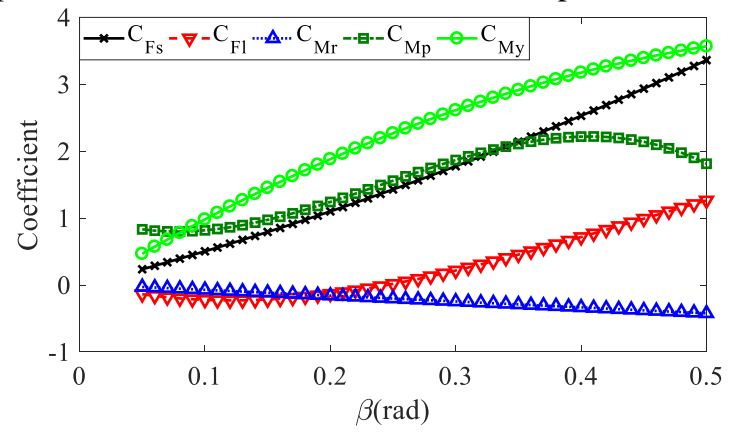

Fig. 6. Aerodynamic coefficients with respect to yaw angle. 


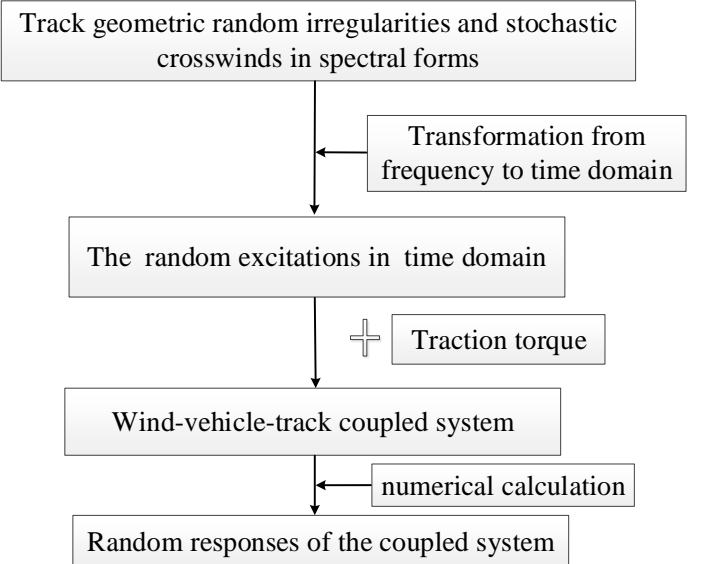

Fig. 10. Analysis procedures of the stochastic wind-vehicle-track coupled system.

very good consistency with the original spectrum. The results of the crosswind speed are presented in Fig. 7 (c) and (d). The good consistency between the simulation PSD of the fluctuating wind speed and its original PSD is also observed.

To gain the confidence of the vehicle-track model, the validation is performed against the measurement data acquired from China high-speed network. The configurations of the accelerometers on the carbody are illustrated in Fig.8. The same work conditions are set in the numerical simulation. It should be noticed that the parameters in the author's previous work [35] are adopted to conduct the following analysis. Fig.9 presents the lateral and vertical accelerations of the carbody in time and frequency domains. It indicates that the amplitude and the dominant frequency of the simulations show good consistency with the experimental tests. The peaks appearing at $0.9 \mathrm{~Hz}$ and $2.8 \mathrm{~Hz}$ are close to the natural frequencies of the carbody pitch and roll, respectively. Hence, the present vehicletrack coupled model properly describes the physical characteristics of the vehicle-track system.

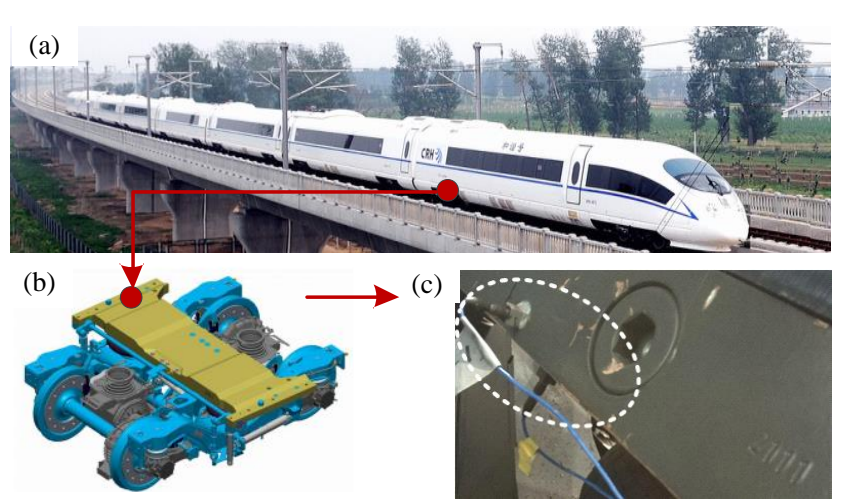

Fig. 8. Configurations of sensors on carbody: the high-speed train (a), the motor bogie (b) and the monitoring point (c).

\section{ANALYSIS OF THE AXLE-BOX BEARING IN THE TIME AND FREQUENCY DOMAINS}

In this section, the effects of the crosswinds on the ABBs are investigated in the time and frequency domains. During the simulations, the vehicle runs along a straight line at a commercial running speed of $300 \mathrm{~km} / \mathrm{h}$ and is excited by the track irregularities, crosswinds, gear meshing, and traction torques. The mean crosswind speed is set to $5 \mathrm{~m} / \mathrm{s}$. Fig. 10 illustrates the simulation procedure of the wind- vehicle-track coupled system. Fig. 11 shows the resulting roller-raceway contact forces in time and frequency domains. It is seen that the crosswinds have clear effects on the roller-raceway contact forces. Without crosswinds, the maximum roller-raceway contact forces of each row roller of the same double-row TRBs are basically the same. However, the crosswind contributes to the maximum roller-raceway contact forces of row 1 (in Figs. 11 (a)), which are higher than those of row 2 (in Figs. 11 (b)). The TRBs in the windward side (in Figs. 11 (d) and (e)) also show a similar pattern with the TRBs in the leeside (in Figs. 11
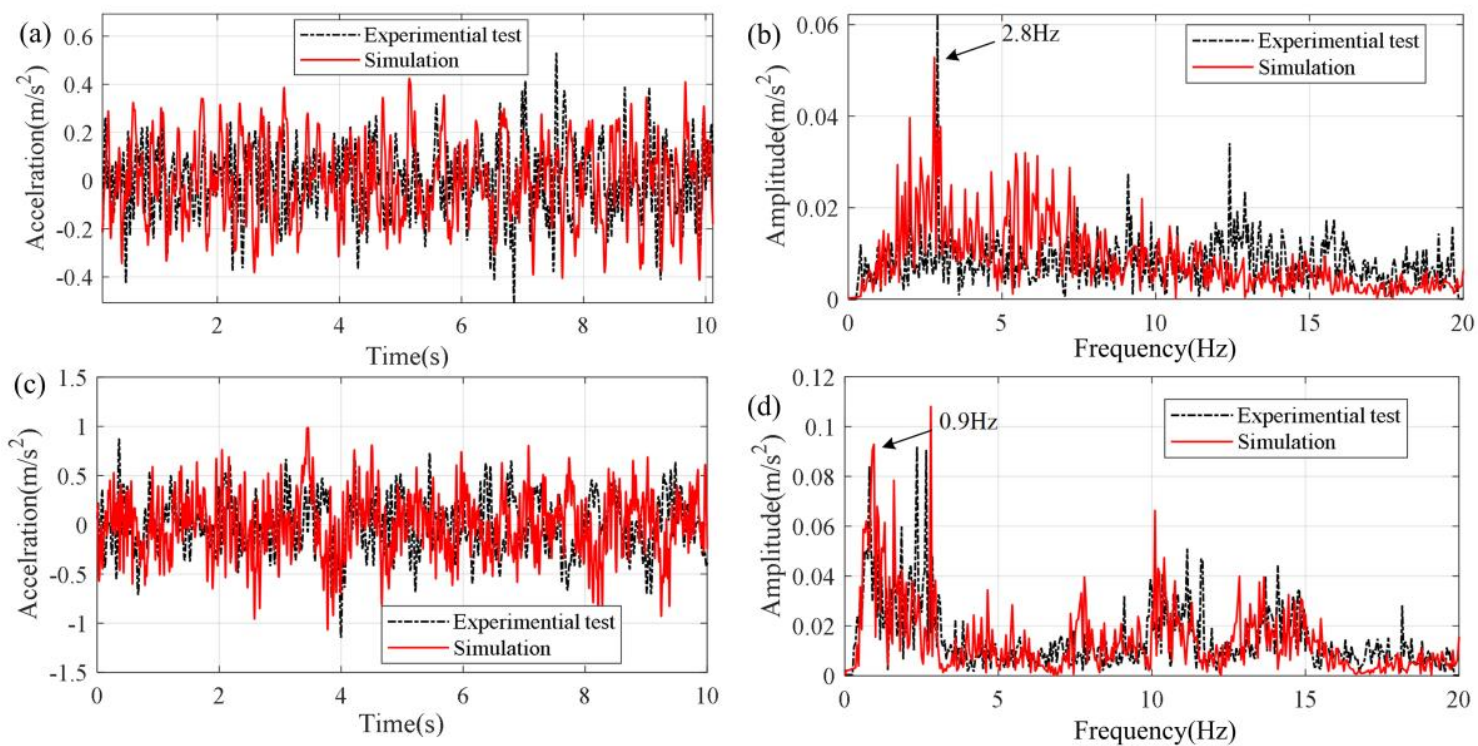

Fig. 9. Validation of vehicle-track model by comparison with experimental test: lateral acceleration of carbody in time domain (a) and frequency domain (b); vertical acceleration of carbody in the time domain (c) and frequency domain (d). 
(a) and (b)). This phenomenon is caused by the relative lateral displacement between the inner and outer ring raceways caused by the crosswinds. Figs. 11 (c) and (f) show the corresponding PSD of the time history in Figs. 11 (a) and (d), respectively. Figs. 11 (c) and (f) indicate that the track irregularities and the crosswinds have a dominant effect on the roller-raceway contact forces at relatively low frequencies $(<100 \mathrm{~Hz})$. Moreover, it presents three peaks at 264.7, 529.3, and $794 \mathrm{~Hz}$, which are relevant to the roller-raceway passing frequency (RPF) and its second (2RPF) and third (3RPF) harmonics, respectively.

Fig. 12 illustrates the maximum contact stress of the TRBs to study the roller raceway contact status in a complex service environment. The maximum contact stress of the TRBs shows a similar pattern with the roller-raceway contact forces. However, the presence of crosswinds causes more local peaks. The maximum contact stress of the TRBs is $1057 \mathrm{MPa}$ in the leeside with an increment of $8.1 \%$ with respect to the result without the crosswinds. For the TRBs located on the windward
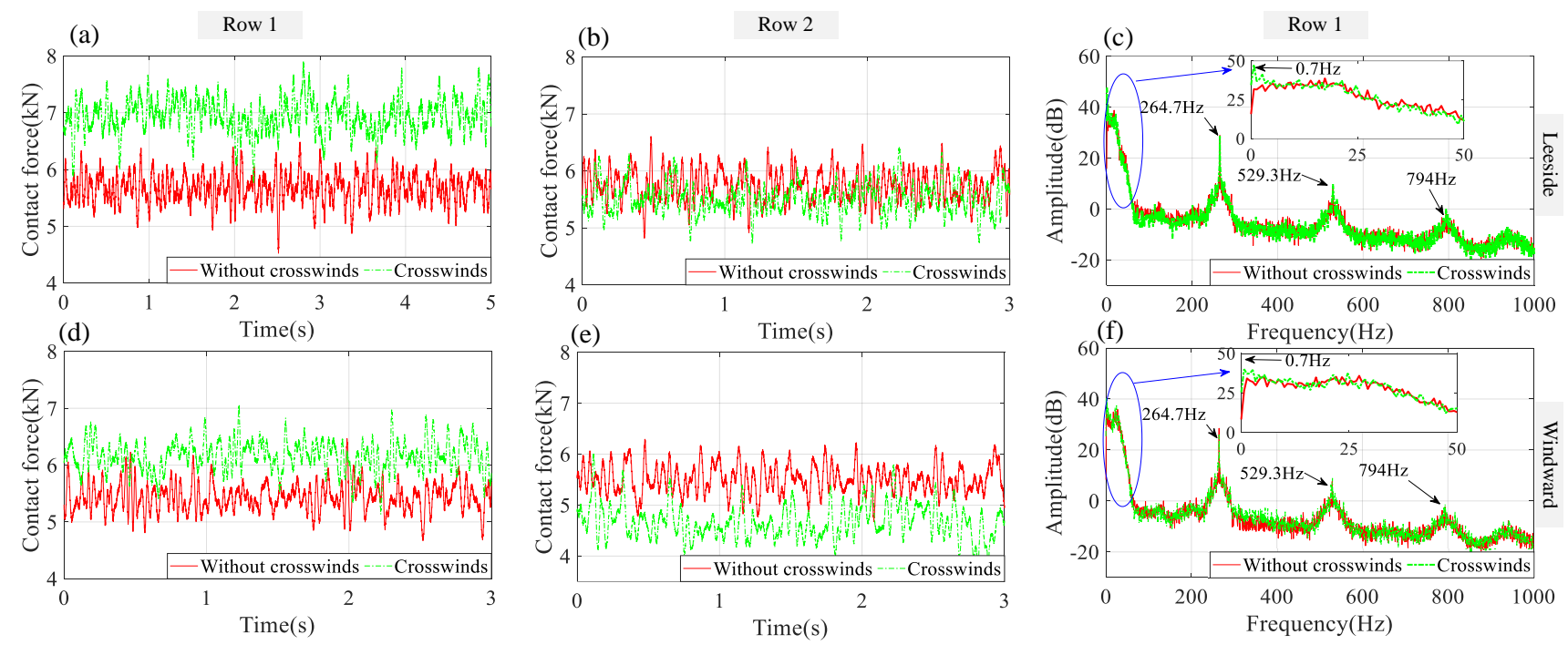

Fig. 11. Time history of roller-raceway contact forces of row1 (a) and row2 (b) for the leeside ABB and the frequency results (c) of row 1 roller-raceway contact forces; time history of roller-raceway contact forces of row1 (c) and row2 (d) for the windward ABB and the frequency results (f) of row 1.
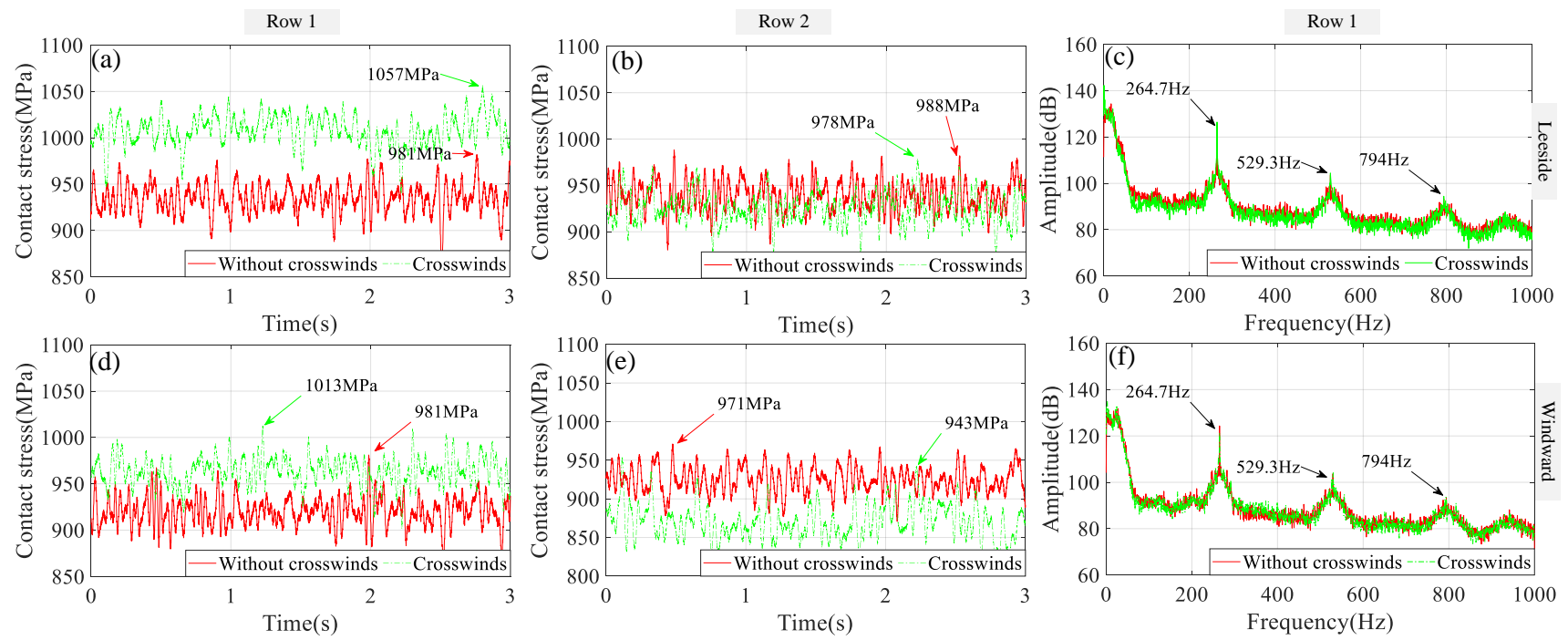

Fig. 12. Time history of roller-raceway contact stress of row1 (a) and row2 (b) for the leeside ABB and the frequency results (c) of row 1 roller-raceway contact stress; time history of roller-raceway contact stress of row1 (c) and row2 (d) for the windward ABB and the frequency results (f) of row 1 rollerraceway contact stress. 
dynamic forces and stress of the leeside ABBs.

\section{STOCHASTIC ANALYSIS OF THE AXLE-BOX BEARING}

In this section, the stochastic responses of the vehicle system, especially the ABBs, are analyzed based on the idea of Monte Carlo method (MCM). According to the results in [42] and the Kolmogorov-Smirnov test results, 500 simulations are enough to describe the full stochastics of the vehicle-track coupled system under steady wind and track irregularities. For accuracy, a total of 1000 simulations are performed in the stochastic analysis. Through the Kolmogorov-Smirnov test, the p-values for all the contact forces and the stresses are lower than 1.5, which means that these responses comply the normal distribution. The normal kernel function is adopted to analyse the PDFs of these responses. To assess the ABBs in the service environments, the wind speed levels are required to satisfy the operation safety of the high-speed train. Hence, the effect of crosswinds on the vehicle running safety is evaluated before the investigation of the stochastics of ABBs.

Fig. 13 shows the results of the wheel-rail forces for the left and right wheels without the crosswinds. Fig. 13 (a) and (b) depict that the lateral and vertical forces are different in different wheels, especially the difference of the vertical wheelrail forces. Figs. 13 (c) and (d) show the probability density function (PDF) of the wheel-rail forces, which depicts that the vertical wheel-rail forces between the two wheels have more significant differences than the lateral forces. Moreover, the vertical wheel-rail of the left wheel is basically higher than that of the right wheel because of the structures of the traction transmission systems. However, the lateral wheel-rail forces exhibit slight differences between the two wheels.

Different crosswind speeds changing from 5 to $25 \mathrm{~m} / \mathrm{s}$ are adopted to investigate the dynamic interactions of the $\mathrm{ABBs}$ within the vehicle-track coupled system under the conditions of the vehicle running safety. The PDFs of the wheel-rail forces and the load reduction factors are presented in Fig.14. It is seen that the increase of the crosswind speed significantly causes the increase of the leeside forces, and also leads to the decrease of
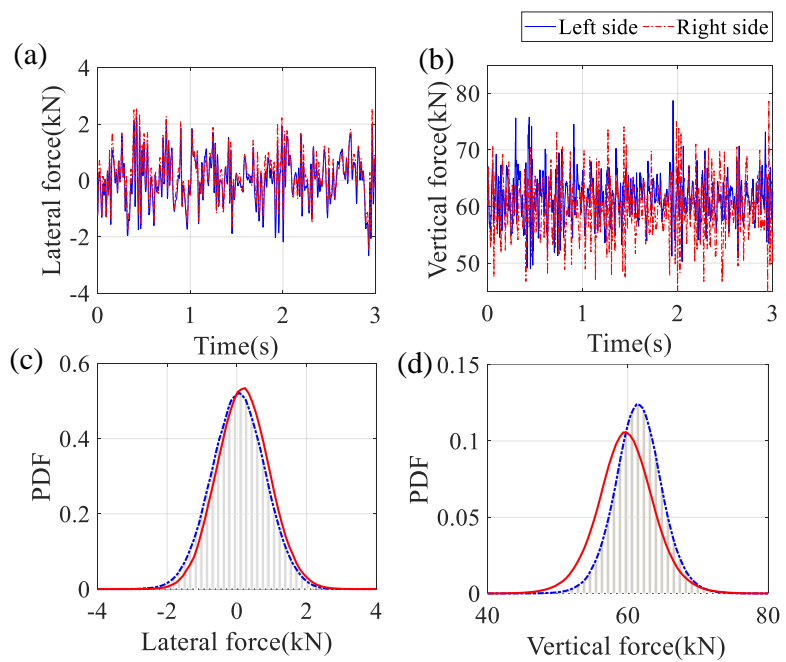

Fig. 13. Time history of the (a) lateral and (b) vertical wheel-rail forces and its PDF (c) and (d) in the left and right sides, respectively. the windward forces. The phenomenon of wheel partial loading is caused by the crosswind. The load reduction factor, which is the ratio of the wheel load reduction amount of one side wheel and the average wheel load of the wheelset under $2 \mathrm{~Hz}$, is an index to assess the running safety of the vehicle system. It is found that the increase of crosswind speed threatens the vehicle running safety. The load reduction factors (LRFs) are within the safety scope (smaller than 0.8) when the wind speeds are lower than $20 \mathrm{~m} / \mathrm{s}$. However, the LRF has a probability of $0.28 \%$ over the safety threshold when the running speeds reach $25 \mathrm{~m} / \mathrm{s}$. Therefore, the maximum safe wind speed of this type of vehicle does not exceed $20 \mathrm{~m} / \mathrm{s}$.

Fig. 15 presents the PDF of the roller-raceway contact stress with different crosswind speeds. In general, the higher crosswind speed results in higher contact stresses of both bearings located on both of the leeside and the windward. Moreover, the $\mathrm{ABB}$ of the leeside bearing suffers higher contact stresses with respect to the windward. The increase of the crosswind speed makes a wider distribution of the PDF. When the crosswind speed is over $20 \mathrm{~m} / \mathrm{s}$, the roller-raceway contact stress may exceed the fatigue stress limit of $1500 \mathrm{MPa}$ [43], which dramatically reduces the service time of bearings. The probability of the contact stress over the fatigue stress reached $1.3 \%$ when the crosswind speed reaches $25 \mathrm{~m} / \mathrm{s}$. TABLE I shows the roller-raceway contact stress of the leeside ABB at a 99\% probability level. It indicates that a higher vehicle running speed leads to a more intense interaction within the ABBs and higher contact stresses. When the crosswind is present, the reliability of the $\mathrm{ABBs}$ cannot be kept at 0.99 at the running speed of $300 \mathrm{~km} / \mathrm{s}$. Thus, the safety and reliability inside the train should be re-evaluated under a complex service 

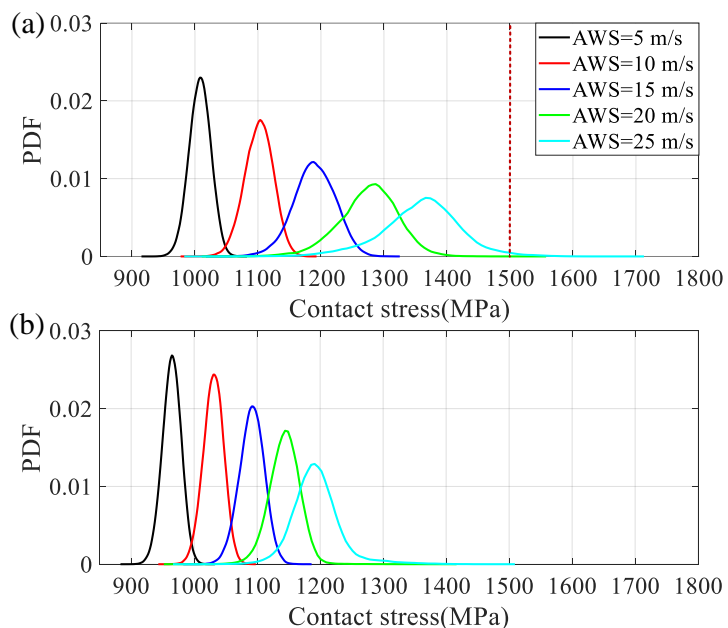

Fig. 15. PDF of the roller-raceway contact stress in the (a) leeside and (b) windward.

environment.

Fig. 16 shows the boxplots of the standard deviation (STD) of the roller-raceway contact stress at different wind speeds with a running speed of $300 \mathrm{~km} / \mathrm{h}$. The lines of the box represent

TABLE I

CONTACT STRESS AT 99\% PROBABILITY LEVEL

\begin{tabular}{ccc}
\hline \hline \multirow{2}{*}{ Wind speed $(\mathrm{m} / \mathrm{s})$} & \multicolumn{2}{c}{ Contact stress $(\mathrm{MPa})$} \\
& $250 \mathrm{~km} / \mathrm{h}$ & $300 \mathrm{~km} / \mathrm{h}$ \\
\hline 0 & 953.5 & 971.9 \\
5 & 1030.0 & 1046.7 \\
10 & 1092.9 & 1151.8 \\
15 & 1161.9 & 1262.3 \\
20 & 1233.1 & 1379.8 \\
25 & 1314.6 & 1508.1 \\
\hline \hline
\end{tabular}

the values of the $25 \%, 50 \%$, and $75 \%$ quantiles from bottom to top. The line below (upper) the box represents the below (upper)-edge values equal to the $25 \%(75 \%)$ quantile minus (plus) the quartile distance. The STD of the contact stress shows a nonlinear increasing tendency with respect to the wind speed. Moreover, the increase of wind speed causes a more significant dispersion of the STD of the contact stress, which brings more randomness to the dynamic behaviours of ABBs, especially when the wind speed is over $15 \mathrm{~m} / \mathrm{s}$. The increased dispersion is also demonstrated by the wider distribution of the PDF shown in Fig. 15.

\section{CONCLUSION}

In this paper, a novel vehicle-track coupled model is proposed herein with comprehensive considerations of the $\mathrm{ABBs}$ and the effects of the random irregularities and unsteady crosswinds. The present model enables more realistic simulations, which are used to reveal the stochastic dynamic behaviours of ABBs during the vehicle operation. The analysis results show that the stochastic crosswind contributes to the dynamic interaction within the ABBs and makes a clear increment of the contact stress. Moreover, the dynamic forces and stresses within the ABB located on the left wheel are higher than those of the right wheel because of the partial loading phenomenon caused by the crosswind. The PDF analysis results indicated that the wheelrail interaction and the $\mathrm{ABBs}$ are sensitive to the crosswinds.
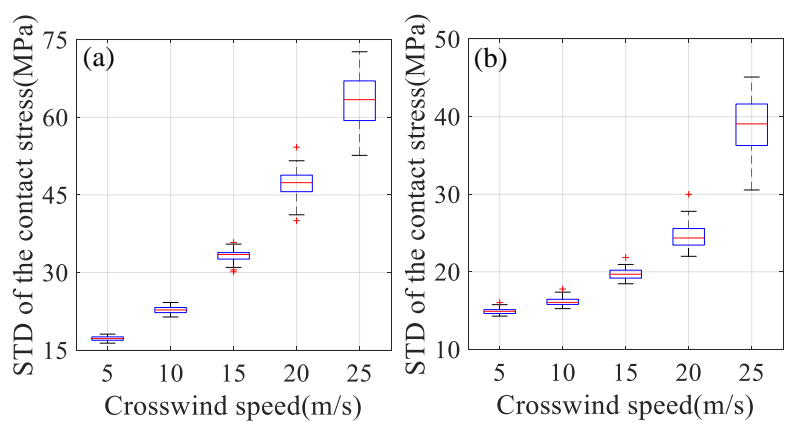

Fig. 16. STD of the roller-raceway contact stress in the (a) leeside and (b) windward.

Even though the running safety of the train is satisfied, the stress of ABBs may exceed the fatigue stress limit at high crosswind speeds, which causes a decrease in the service time of the ABBs. So, random excitations (such as track irregularities and crosswinds) have noticeable effects on the safety of ABBs, which should be adequately considered in the design process of the key components inside the train running in a complex service environment.

\section{ACKNOWLEDGEMENT}

The first author thanks the support of the China Scholarship Council.

\section{REFERENCES}

[1] W. Zhang, "Dynamics of coupled systems in high-speed trains: theory and practice," ed: Beijing: Science Press, 2013.

[2] S. Lu, Q. He, F. Hu, and F. Kong, "Sequential Multiscale Noise Tuning Stochastic Resonance for Train Bearing Fault Diagnosis in an Embedded System," IEEE Transactions on Instrumentation and Measurement, vol. 63, no. 1, pp. 106-116, 2014.

[3] Y. Cheng, Z. Wang, and W. Zhang, "A Novel Condition-Monitoring Method

for Axle-Box Bearings of High-Speed Trains Using Temperature Sensor Signals," IEEE Sensors Journal, vol. 19, no. 1, pp. 205-213, 2019.

[4] S. Leva, A. P. Morando, and P. Colombaioni, "Dynamic Analysis of a HighSpeed Train," IEEE Transactions on Vehicular Technology, vol. 57, no. 1, pp. 107-119, 2008.

[5] P. Wang, T. Mei, J. Zhang, and H. Li, "Self-powered active lateral secondary suspension for railway vehicles," IEEE Transactions on Vehicular Technology, vol. 65, no. 3, pp. 1121-1129, 2015.

[6] L. Yu-Chen, L. Chun-Liang, and Y. Chih-Chieh, "Robust Active Vibration Control for Rail Vehicle Pantograph," IEEE Transactions on Vehicular Technology, vol. 56, no. 4, pp. 1994-2004, 2007.

[7] Z. Wang et al., "Effects of polygonal wear of wheels on the dynamic performance of the gearbox housing of a high-speed train," Proceedings of the Institution of Mechanical Engineers, Part F: Journal of Rail and Rapid Transit, vol. 232, no. 6, pp. 1852-1863, 2018.

[8] Z. Wang, Y. Cheng, G. Mei, W. Zhang, G. Huang, and Z. Yin, "Torsional vibration analysis of the gear transmission system of high-speed trains with wheel defects," Proceedings of the Institution of Mechanical Engineers, Part F: Journal of Rail and Rapid Transit, p. 095440971983379, 2019.

[9] V. Garg, Dynamics of railway vehicle systems. Elsevier, 2012.

[10] W. Zhai and X. Sun, "A detailed model for investigating vertical interaction between railway vehicle and track," vehicle system dynamics, vol.23, no. S1, pp. 603-615, 1994.

[11] J. C. Nielsen and A. Igeland, "Vertical dynamic interaction between train and track influence of wheel and track imperfections," Journal of sound and vibration, vol. 187, no. 5, pp. 825-839, 1995.

[12] W. Zhai, K. Wang, and C. Cai, "Fundamentals of vehicle-track coupled dynamics," Vehicle System Dynamics, vol. 47, no. 11, pp. 1349-1376, 2009.

[13] Z. Wang, G. Mei, Q. Xiong, Z. Yin, and W. Zhang, "Motor car-track spatial coupled dynamics model of a high-speed train with traction transmission systems," Mechanism and Machine Theory, vol. 137, pp. 386-403, 2019. 
[14] W. Zhai et al., "High-speed train-track-bridge dynamic interactions -Part I: theoretical model and numerical simulation," International Journal of Rail Transportation, vol. 1, no. 1-2, pp. 3-24, 2013.

[15] W. Zhai et al., "High-speed train-track-bridge dynamic interactions -Part II: experimental validation and engineering application," International Journal of Rail Transportation, vol. 1, no. 1-2, pp. 25-41, 2013.

[16] Y. Song, Z. Liu, H. Wang, J. Zhang, X. Lu, and F. Duan, "Analysis of the galloping behaviour of an electrified railway overhead contact line using the non-linear finite element method," Proceedings of the Institution of Mechanical Engineers, Part F: Journal of Rail and Rapid Transit, vol. 232, no. 10, pp. 23392352, 2018.

[17] Y. Song, Z. Liu, H. Wang, X. Lu, and J. Zhang, "Nonlinear analysis of wind-induced vibration of high-speed railway catenary and its influence on pantograph-catenary interaction," Vehicle System Dynamics, vol. 54, no. 6, pp. 723-747, 2016.

[18] M. Yu, J. Liu, D. Liu, H. Chen, and J. Zhang, "Investigation of aerodynamic effects on the high-speed train exposed to longitudinal and lateral wind velocities," Journal of Fluids and Structures, vol. 61, pp. 347-361, 2016.

[19] Y. L. Xu and Q. S. Ding, "Interaction of railway vehicles with track in cross-winds," Journal of Fluids and Structures, vol. 22, no. 3, pp. 295-314, 2006.

[20] F. Immovilli, C. Bianchini, M. Cocconcelli, A. Bellini, and R. Rubini, "Bearing Fault Model for Induction Motor With Externally Induced Vibration," IEEE Transactions on Industrial Electronics, vol. 60, no. 8, pp. 3408-3418, 2013.

[21] T.-J. Kim, S.-M. Hwang, K.-T. Kim, W.-B. Jung, and C.-U. Kim, "Comparison of dynamic responses for IPM and SPM motors by considering mechanical and magnetic coupling," IEEE Transactions on Magnetics, vol. 37, no. 4, pp. 2818-2820, 2001.

[22] B. Li, M.-Y. Chow, Y. Tipsuwan, and J. C. Hung, "Neural-networkbased motor rolling bearing fault diagnosis," IEEE transactions on industrial electronics, vol. 47, no. 5, pp. 1060-1069, 2000.

[23] M. Kang, J. Kim, L. M. Wills, and J.-M. Kim, "Time-Varying and Multiresolution Envelope Analysis and Discriminative Feature Analysis for Bearing Fault Diagnosis," IEEE Transactions on Industrial Electronics, vol. 62, no. 12 , pp. $7749-7761,2015$.

[24] C. P. Mbo'o and K. Hameyer, "Fault diagnosis of bearing damage by means of the linear discriminant analysis of stator current features from the frequency selection," IEEE Transactions on Industry Applications, vol. 52, no. 5, pp. 3861-3868, 2016.

[25] A. Palmgren, "Ball and roller bearing engineering," Philadelphia: SKF Industries Inc., 1959, 1959.

[26] A. Jones, "A general theory for elastically constrained ball and radial roller bearings under arbitrary load and speed conditions," Journal of Basic Engineering, vol. 82, no. 2, pp. 309-320, 1960.

[27] T. A. Harris, Rolling bearing analysis. John Wiley and sons, 2001.

[28] S. Andréason, "Load distribution in a taper roller bearing arrangement considering misalignment," Tribology, vol. 6, no. 3, pp. 84-92, 1973.

[29] S. Kabus, M. R. Hansen, and O. Mouritsen, "A new quasi-static multidegree of freedom tapered roller bearing model to accurately consider non-Hertzian contact pressures in time-domain simulations," Proceedings of the Institution of Mechanical Engineers, Part K: Journal of Multi-body Dynamics, vol. 228, no. 2, pp. 111-125, 2014.

[30] V.-C. Tong and S.-W. Hong, "The effect of angular misalignment on the running torques of tapered roller bearings," Tribology International, vol. 95, pp. 76-85, 2016.

[31] V.-C. Tong and S.-W. Hong, "Characteristics of tapered roller bearing with geometric error," International Journal of Precision Engineering and Manufacturing, vol. 16, no. 13, pp. 2709-2716, 2015.

[32] I. Bercea, S. Cretu, and D. Nélias, "Analysis of double-row tapered roller bearings, Part I-Model," Tribology transactions, vol. 46, no. 2, pp. 228-239, 2003.

[33] D. Nelias, I. Bercea, and N. Mitu, "Analysis of double-row tapered roller bearings, Part II-results: prediction of fatigue life and heat dissipation," Tribology transactions, vol. 46, no. 2, pp. 240-247, 2003.

[34] L. Yang, T. Xu, H. Xu, and Y. Wu, "Mechanical behavior of double-row tapered roller bearing under combined external loads and angular

misalignment," International Journal of Mechanical Sciences, vol. 142-143, pp. 561-574, 2018.

[35] Z. Wang, W. Zhang, Z. Yin, Y. Cheng, G. Huang, and H. Zou, "Effect of vehicle vibration environment of high-speed train on dynamic performance of axle box bearing," Vehicle System Dynamics, vol. 57, no. 4, pp. 543-563, 2018. [36] T. A. Harris and M. N. Kotzalas, Advanced concepts of bearing technology: rolling bearing analysis. CRC press, 2006.
[37] W. Weaver Jr, S. P. Timoshenko, and D. H. Young, Vibration problems in engineering. John Wiley \& Sons, 1990.

[38] W. Zhai, "Vehicle-track coupling dynamics," Science, Beijing, 2007.

[39] R. Cooper, "Atmospheric turbulence with respect to moving ground vehicles," Journal of wind engineering and industrial aerodynamics, vol. 17, no. 2, pp. 215-238, 1984.

[40] B. EN, "14067-6, railway applications-aerodynamics-part 6: requirements and test procedures for cross wind assessment," European Committee for Standardization, Brussels, 2010.

[41] M.-G. Yu, J.-Y. Zhang, K.-Y. Zhang, and W.-H. Zhang, "Study on the operational safety of high-speed trains exposed to stochastic winds," Acta Mechanica Sinica, vol. 30, no. 3, pp. 351-360, 2014.

[42] L. Xu and W. Zhai, "A model for vehicle-track random interactions on effects of crosswinds and track irregularities," Vehicle system dynamics, vol. 57, no. 3, pp. 444-469, 2019.

[43] O. I. d. Normalización, Rolling Bearings: Dynamic Load Ratings and Rating Life. ISO, 2007.

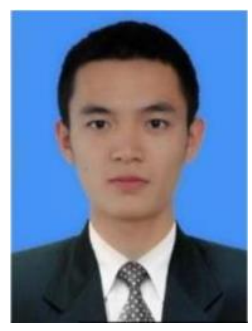

Zhiwei Wang (S'19) received the undergraduate degree of Structural Engineering Analysis in Southwest Jiaotong University. Currently he is a Ph.D. student at State Key Laboratory of Traction Power, Southwest Jiaotong University. His recent researches are fault diagnosis, vehicle-track coupled dynamics and

bearing dynamics.

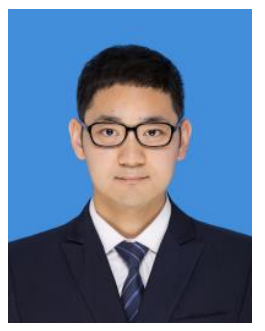

Yang Song (S'16-M'19) received the $\mathrm{Ph} . \mathrm{D}$. degree in electrical engineering from Southwest Jiaotong University, Sichuan China, in 2018.

$\mathrm{He}$ is currently a Research Fellow with the Institute of Railway Research, School of Computing and Engineering, University of Huddersfield, UK. His research interests involve the assessment of railway pantograph-catenary interaction, the wind-induced vibration of long-span structures of railway transportation, and the coupling dynamics in railway engineering.

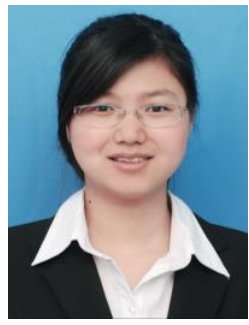

Zhonghui Yin received the undergraduate degree of Vehicle Engineering at the Hefei University of Technology. Currently, she is a Ph.D. student at the State Key Laboratory of Traction Power, Southwest Jiaotong University. Her recent researches are vehicle dynamics and aerodynamics.

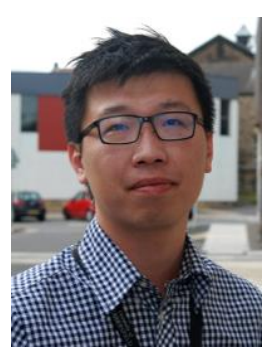

Ruichen Wang awarded the $\mathrm{PhD}$ in School of Computing and Engineering, at University of Huddersfield, UK, in 2016. $\mathrm{He}$ is now an Industrial Fellow at Institute of Railway Research (University of Huddersfield). His current research interests include vehicle dynamics, regenerative suspension, condition monitoring. 


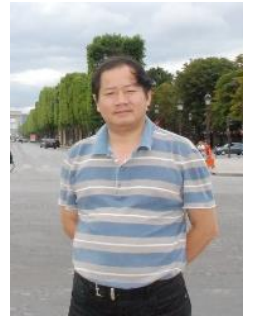

Weihua Zhang received the B.Sc. degree in mechanical automation from Southwest Jiaotong University, China, in 1983, the M.Sc. degree in engineering mechanics from the Southwest Jiaotong University, China, in 1989, and the Ph.D. degree in vehicle operation engineering from the Southwest Jiaotong University, China, in 1996. He is currently a Professor of State Key Laboratory of Traction Power, Southwest Jiaotong University, Chengdu, China. His research interests include rail vehicle design theory and structural reliability; vehicle system dynamics and control; pantograph-catenary relation; measurement and test technology. 